\title{
クラッド・チップ押出し法による $\mathrm{Nb}_{3} \mathrm{Sn}$ の線材化*
}

$\begin{array}{lllll}\text { 斎 } & \text { 藤 } & \text { 栄** } & \text { 和 知 高 志 } \\ \text { 安達 和 彦*** } & \text { 花 田 修 治** }\end{array}$

J. Japan Inst. Metals, Vol. 56, No. 8 (1992), pp. 960-964

Fabrication of $\mathrm{Nb}_{3} \mathrm{Sn}$ Superconducting Wire by the Clad-Chip Extrusion Method

\author{
Sakae Saito*, Takashi Wachi*, \\ Kazuhiko Adachi** and Shuji Hanada* \\ *Institute for Materials Research, Tohoku University, Sendai \\ **Advanced Technology Research Department, Technical Research Center, \\ Nippon Stainless Steel Co., Ltd., Jouetsu
}

The Clad-Chip Extrusion (CCE) method is applied to a fabrication process of $\mathrm{Nb}_{3} \mathrm{Sn}$ superconducting wires. This method is characterized by extruding the chipped $\mathrm{Nb}-\mathrm{Sn}$ clad sheets with the intended chemical composition. Ti-foil cladding to the $\mathrm{Nb}$-Sn composite sheet is also studied as a method of titanium addition. An extruded $\mathrm{Nb}-\mathrm{Sn}$ composite bar shows good workability in wire drawing up to a relatively high reduction ratio, $R$ of $10^{6}$, where $R$ is the cross-section ratio of an initial billet to a final wire.

The CCE-processed $\mathrm{Nb}_{3} \mathrm{Sn}$ wire heat-treated under the optimum condition shows the critical transition temperature, $T_{\mathrm{c}}$ of $17.8 \mathrm{~K}$ and the critical current density, $J_{\mathrm{c}}$ of $1.18 \times 10^{8} \mathrm{~A} \cdot \mathrm{m}^{-2}$ in the applied magnetic field of $20 \mathrm{~T}$ at $4.2 \mathrm{~K}$. The upper critical field, $B_{\mathrm{c} 2}^{*}(4.2 \mathrm{~K})$ is estimated as $23.4 \mathrm{~T}$ using the Kramer plot. (Received March 13, 1992)

Keywords: clad-chip extrusion method, superconductor, $\mathrm{Nb}_{3} \mathrm{Sn}$ wire, critical transition temperature, critical current density

\section{I．緒言}

$\mathrm{Nb}_{3} \mathrm{Sn}$ は極細多芯超伝導導体として実用化され，高磁 界用超伝導マグネットに用いられている.これには線材化 方法としてブロンズ法(1)-(3)の成功と高磁界での $J_{\mathrm{c}}$ 特性を 改善する Ti 添加(4)(5)の効果が大きく寄与している. ブロ ンズ法とは Nb とブロンズを複合加工し，最終的に拡散熱 処理により $\mathrm{Nb}_{3} \mathrm{Sn}$ 化合物を得るというものであるが，こ の手法に打ける問題点はブロンズの加工硬化が大きいため 繰り返し中間焼鈍が必要なことや Sn 濃度を高くできない ことなどである．そのためブロンズを使わない他の線材化 法も次々と考案され, 外部拡散法 ${ }^{(6)}, i n$-situ 法 ${ }^{(7)}{ }^{(8)}$, 内部 拡散法(9)などが報告されてきた。 また，in-situ法の変形 とも見られる $\mathrm{Nb}$ と $\mathrm{Cu}$ の混合粉末を用いる線材化方 法(10)(11)や，後のチューブ法へと発展を遂げるブロンズ芯

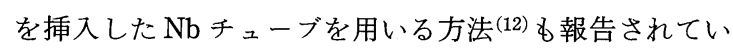
る.さらに，ブロンズは使用するが䇴から出発するため通
常のブロンズ法のように大きな加工度を必要としないジェ リーロール法(13), 高濃度の $\mathrm{Sn}$ を含む $\mathrm{Sn}-\mathrm{Cu}$ 合金または $\mathrm{Sn}$ そのものを芯として Cuと Nbのチューブを被覆して 複合加工するニオブ・チューブ法(14)(15), $\mathrm{Nb}$ 粉末圧粉体 の空隙に溶融 Sn を浸透させ伸線加工を行い, Nb-Sn 複合 体線中の $\mathrm{Nb}$ と $\mathrm{Sn}$ を直接反応させる方法である浸透法 ${ }^{(16)}$, なども開発された.なかでも，ニオブ・チューブ法による $1 \mathrm{~mol} \% \mathrm{Ti}$ 添加 $\mathrm{Nb}_{3} \mathrm{Sn}$ 極細多芯線は $20 \mathrm{~T}$ で $2 \times 10^{8} \mathrm{~A}$. $\mathrm{m}^{-2}$ の $J_{\mathrm{c}}$ 值が得られている(17).

ところで, 我々は $\mathrm{Nb}_{3} \mathrm{Al}$ の線材化方法としてクラッド ・チップ押出し法 (以下では CCE 法と記す)を提案し, そ の検討結果を報告してきた(18)-(20). この手法は目的の化 学組成を有するように $\mathrm{Nb}$ と $\mathrm{Al}$ の薄板を積層させたクラ ッド薄板を作製し，それを細片化(チップ化)したものを出 発材料とし，これらを充填したビレットを押出し加工して 得られた棒状の Nb-Al 複合体を伸線加工し, 最後に拡散 熱処理により $\mathrm{Nb}_{3} \mathrm{Al}$ 線材を得るといら方法である. CCE 法により作製した $\mathrm{Nb}_{3} \mathrm{Al}$ 線材はこれまでに報告されてい

\footnotetext{
*1990年 9 月日本金属学会秋期大会に括いて発表

** 東北大学金属材料研究所

*** 日本ステンレス(侏)技術研究所先端技術研究部

$†$ 東北大学金属材料研究所, 現在 : 日本ステンレス(侏技術研究所ステンレス鋼研究部
} 
る他の手法による線材の最高の超伝導特性と比肩できる值 を示す. このように CCE 法は $\mathrm{Nb}_{3} \mathrm{Al}$ の線材化方法として 有効であるが, 本手法を $\mathrm{Nb}_{3} \mathrm{Sn}$ の線材化に適用した研究 例はこれまでに報告されていない。

本研究の第一の目的は CCE 法による $\mathrm{Nb}_{3} \mathrm{Sn}$ の線材化を 検討することである. 第二の目的は $\mathrm{Nb}_{3} \mathrm{Sn}$ の特性改善に これまで最も有効とされている Ti の添加方法を CCE 法 に括いて検討することである．他の手法では $\mathrm{Nb}$ 側 (4) (21) あるいはブロンズマトリックス側(22)(23)に合金化すること により Ti添加されているが，CCE 法では二通りの Ti 添 加方法が考えられる. 一つは従来と同じ方法で，あらかじ め積層素板に合金化して添加する場合，もら一つは CCE 法の特徵であるクラッドする段階で金属 Ti を積層化して 添加する場合である. 本研究ではその両者, すなわら, $\mathrm{Nb}$ 素板に合金化する場合と $\mathrm{Ti}$ 箔を積層化する場合を検 討した.

\section{II. 実 験 方 法}

$\mathrm{CCE}$ 法で出発素材となるクラッド薄板として次の 3 種 類を準備した. (1) $\mathrm{Ti}$ 無添加の場合は厚さ $1 \mathrm{~mm}$ の $\mathrm{Nb}$ 板 の表裏に厚さ $0.3 \mathrm{~mm}$ の $\mathrm{Sn}$ 薄板を重ねてクラッド圧延 し, 最終的に厚さ $0.2 \mathrm{~mm}$ の $\mathrm{Sn}-\mathrm{Nb}-\mathrm{Sn}$ 三層薄板を作製し た. (2) Ti $\mathrm{Nb}$ に合金化して添加する場合はアーク溶解 により $\mathrm{Nb}-1 \mathrm{~mol} \% \mathrm{Ti}$ 合金を得，熱間および冷間圧延によ り厚さ $0.2 \mathrm{~mm}$ の薄板とした後, $1273 \mathrm{~K}$ で $108 \mathrm{ks}$ の真空 焼鈍を行った．その薄板の表裏に厚さ $0.05 \mathrm{~mm}$ の $\mathrm{Sn}$ 薄 板を重ねてクラッド圧延し，最終的に厚さ $0.16 \mathrm{~mm}$ の $\mathrm{Sn}-\mathrm{Nb}$ (Ti)-Sn 三層クラッド薄板を作製した. (3) Ti 管を積 層化して添加する場合は厚さ $15 \mu \mathrm{m}$ の Ti 䇴の表裏に厚さ $0.5 \mathrm{~mm}$ の $\mathrm{Nb}$ 板を重ね, さらにその両側に厚さ $0.3 \mathrm{~mm}$ の $\mathrm{Sn}$ 薄板を重ねてクラッド圧延し，最終的に厚さ 0.2 $\mathrm{mm}$ の Sn-Nb-Ti-Nb-Sn 五層クラッド薄板を作製した．積 層化して添加した $\mathrm{Ti}$ 量は約 $1.5 \mathrm{~mol} \%$ となる．また，上 記 3 種類のクラッド薄板に扣ける $\mathrm{Sn}$ 含有量は約 23 $\mathrm{mol} \%$ である.それらを約 $5 \mathrm{~mm}$ 角の細片に裁断し，約 $130 \mathrm{~g}$ を内径 $24 \mathrm{~mm}$, 外径 $40 \mathrm{~mm}$, 長さ $65 \mathrm{~mm}$ の純銅容 器に $50 \mathrm{kN}$ の荷重で圧縮充填して押出し用ビレットとし た.そのビレットをダイス半角 $45^{\circ}$ のダイスを用いて，押 出し比 $5(\phi 40 \mathrm{~mm} \rightarrow \phi 18 \mathrm{~mm})$ の条件で押出し加工を行っ た. 押出し材の銅シースを切削して除去し, 直径 $8.3 \mathrm{~mm}$ の $\mathrm{Nb}-\mathrm{Sn}(-\mathrm{Ti})$ 複合体を得た。これに外径 $10.4 \mathrm{~mm}$, 内径 $8.4 \mathrm{~mm}$ の $\mathrm{Nb}$ 管でシースを施した後, 内径 $10.5 \mathrm{~mm}$, 外 径 $40 \mathrm{~mm}$, 長さ $60 \mathrm{~mm}$ の 8-2 黄銅容器内に挿入し, 押出 し比 5 で押出しを行った. 引き続き直径 $10.6 \mathrm{~mm}$ まで溝 ロール圧延した後，硝酸で 8-2 黄銅シースを除去し，直径 $3 \mathrm{~mm}$ の Nb-Sn(-Ti) 複合体を得た. これを26本集束して 外径 $18.5 \mathrm{~mm}$, 内径 $16 \mathrm{~mm}$ の $\mathrm{Nb}$ 管に充填し, それを内 径 $18.6 \mathrm{~mm}$, 外径 $40 \mathrm{~mm}$, 長さ $60 \mathrm{~mm}$ の $7-3$ 黄銅容器内
に挿入し，押出し比 5 で押出しを行った. 押出し材を溝 ロール圧延後，可能なところまで線引き加工を行った．以 上の工程はすべて室温で行い, 最終工程まで熱処理は加え ず伸線加工した。

得られた各 $\mathrm{Nb}-\mathrm{Sn}(-\mathrm{Ti})$ 線材に $\mathrm{Nb}_{3} \mathrm{Sn}$ 生成熱処理を施し, $4.2 \mathrm{~K}$ で $14.4 \mathrm{~T}$ (一部 $23 \mathrm{~T}$ ) までの磁界中で四端子法によ り臨界電流 $\left(I_{\mathrm{c}}\right)$ を測定した. $I_{\mathrm{c}}$ の評価基準は $0.1 \mathrm{mV} / \mathrm{m}$ で ある. $J_{\mathrm{c}}$ は $I_{\mathrm{c}}$ を各線材の断面積(外周のシース部を除いた $\mathrm{Nb}_{3} \mathrm{Sn}$ 部の断面積) で除して求めた。な特，断面積の測定 は画像解析装置で行った。また，臨界温度 $\left(T_{\mathrm{c}}\right)$ の測定は 標準的な四端子法で行い, 中点の值を $T_{\mathrm{c}}$ とした.

\section{III. 結果および考察}

\section{1. 線材化プロセスにおける加工性}

良好な超伝導特性を示す $\mathrm{Nb}_{3} \mathrm{Sn}$ 線材を得るためには $\mathrm{Nb}-\mathrm{Sn}$ 複合体を均一に塑性変形させることが必要である. そのためには，第一に層界面に波状の凹凸がない良好なク ラッド材を得ることが必要である. 流動応力に大きな差が ある金属材料の積層材の圧延では種々の形態の不均一変形 すなわち塑性不安定現象が起こる(24)-(26)ことが知られて いる. 本実験に拈いて, 変形抵抗の高い $\mathrm{Nb}$ 層(硬層)を内 側にし, 変形抵抗の低いSn 層(軟層)を外側にした構造と することにより，0.16 mm の厚さまで積層界面に凹凸の ない良好な $\mathrm{Sn}-\mathrm{Nb}(\mathrm{Ti})-\mathrm{Sn}$ 三層クラッド薄板が得られた。 しかし，反対に硬層の $\mathrm{Nb}$ を外にした場合は，内側の $\mathrm{Sn}$ が圧延方向に蛇行し，圧下率の増加とともに振幅を増加さ せ，遂には外側の $\mathrm{Nb}$ を破断させる現象がみられた。この ように軟層と硬層の積層の順序が変形の不均一性に大きく 影響を与える。積層材の圧延に拈ける不均一変形に影響を 与える因子は，構成素材の延性や変形抵抗差等の材料因 子, 構成材料の体積比(厚さ比)や圧下率, ワークロール径 等の加工時の幾何学的因子，あるいは層表面とロールの間 の摩擦条件の差異等のトライボロジー的因子など数多くあ り，その過程は非常に複雑である ${ }^{(24)}$ が，本実験のように 軟相と硬相の積層の順序が不均一変形に大きく影響を与え る場合もある.

$\mathrm{Nb}-\mathrm{Sn}$ クラッド材細片を充填した直径 $40 \mathrm{~mm}$ の純銅ビ レットの冷間押出し加工時の最大押出し荷重は $880 \mathrm{kN}$ で あった． Nb-Al の場合は 8-2 黄銅を用いた(18)が， Nb-Sn の場合は純銅を用いることにより押出しを良好に行うこと ができた. Nb-Sn クラッド材は Nb-Al クラッド材よりも 変形抵抗が低く, そのため黄銅よりも変形抵抗の低い純銅 シースを用いての押出しが可能であったと思われる.

Fig. 1(a) (b)に押出し材の横断面組織 ((a) は Ti 無添加 材, (b)は Ti 積層化添加材)を示す. これからわかるよう に, 押出し加工に拈いては比較的均一な変形が生じてい る. その後の伸線過程に括いては加工度, $R$ (断面減少率 =初期断面積 $/$ 伸線後の断面積 $)$ にして $1.1 \times 10^{6}(\mathrm{Nb}$ 厚さ 

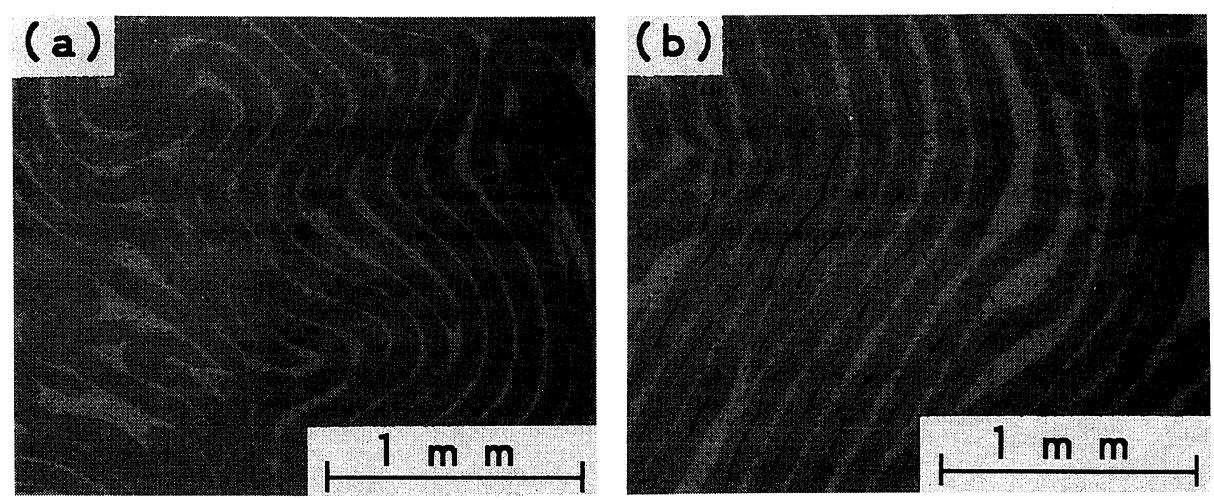

Fig. 1 Cross-section of extruded rod: (a) Nb-Sn composite, (b) Nb-Sn composite with Ti-foil cladding addition.

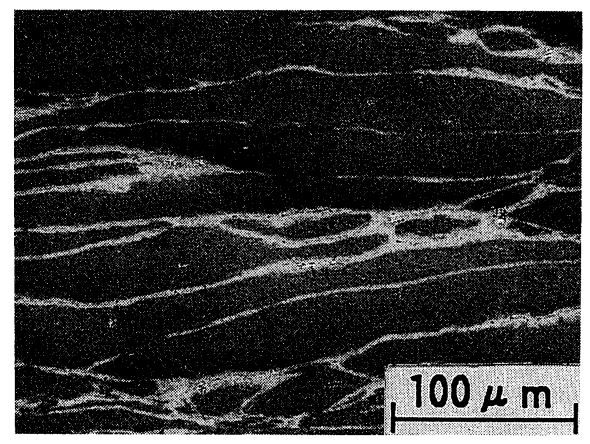

Fig. 2 Longitudinal section of the CCE processed $\mathrm{Nb}-\mathrm{Sn}$ composite wire with an the reduction of $2.64 \times$ $10^{5}$ in area.

に換算すると約 $0.2 \mu \mathrm{m})$ まで断線することなく加工でき た.な拉，ここでの初期断面積とは押出し加工に扣けるビ レットの断面積である. しかしながら， Fig. 2 に示すよ らに $R=2.64 \times 10^{5}$ での線材断面ではすでに不均一塑性流 動が生じて拈り， Nb-Sn 複合体は $\mathrm{Nb}-\mathrm{Al}$ の場合 ${ }^{(19)}$ のよう に $R>10^{6}$ の高加工度までの均一な塑性変形は困難であ る.これは $\mathrm{Sn}$ が $\mathrm{Al}$ よりも変形抵抗が低い上に $\mathrm{Nb}$ の加 工硬化に伴って $\mathrm{Nb}$ と $\mathrm{Sn}$ の流動応力の差が拡大していく ことにより不安定な塑性流動が生じやすくなったためと思 われる。

\section{2. 超伝導特性}

Fig. 3, 4 に低温長時間(973 K-345.6 ks)の一段処理と その前に高温短時間熱処理を加えた二段熱処理を施した $\mathrm{Ti}$ 無添加，扣よび $\mathrm{Ti} \mathrm{Nb}$ に合金添加した各 $\mathrm{Nb}_{3} \mathrm{Sn}$ 線 材の $J_{\mathrm{c}}-B$ 曲線を示す。段熱処理により $J_{\mathrm{c}}$ 特性の改善が 可能であるが，その組合せ方により特性は変化する. 一段 目の温度が高すぎると $J_{\mathrm{c}}$ 特性は低下するが，これは粒成 長が生じたためと考えられる。粒成長を抑制しながら十分 に拡散を進行させるような熱処理が最適条件となる。な

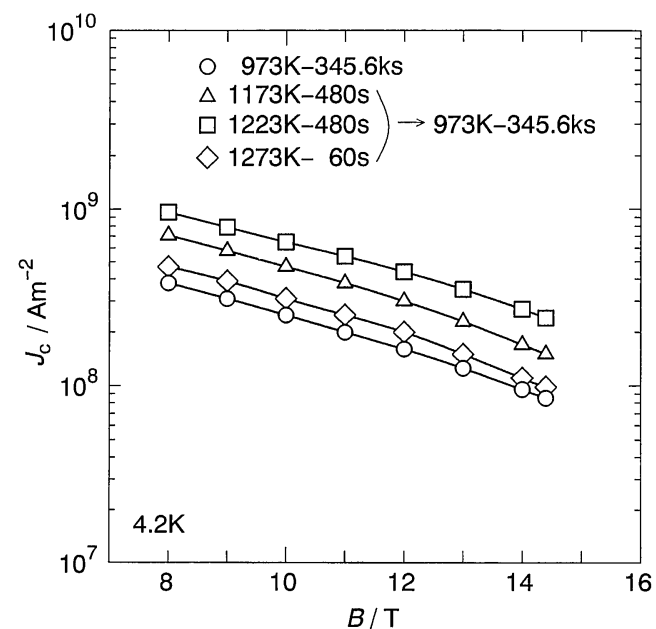

Fig. $3 J_{c}-B$ curve for the $\mathrm{CCE}$ processed $\mathrm{Nb}_{3} \mathrm{Sn}$ wires. Wires were heat-treated under the quoted conditions.

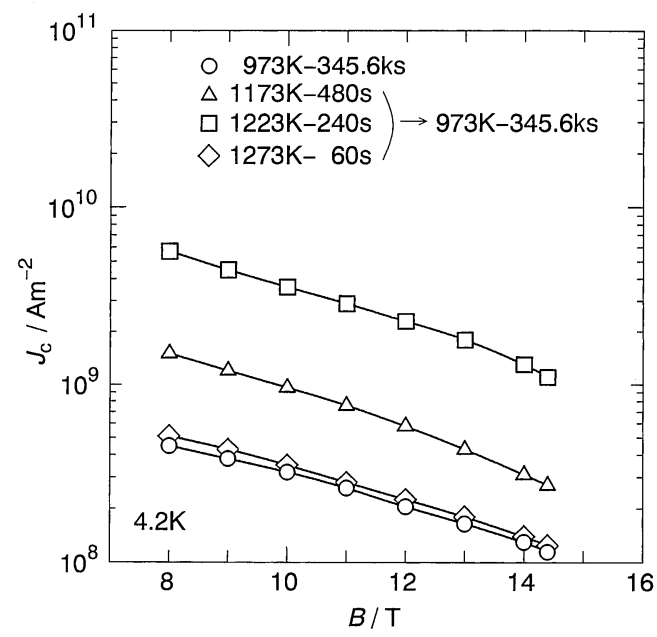

Fig. $4 J_{\mathrm{c}}-B$ curve for the $\mathrm{CCE}$ processed $\mathrm{Nb}_{3} \mathrm{Sn}$ wires with Ti alloying addition. Wires were heat-treated under the quoted conditions. 
お，ここでの二段熱処理はブロンズ法(27)(28)で検討されて いるような低温長時間の後, 高温短時間処理を行うもので はないが，本試料の場合は図中に示したような条件で $J_{\mathrm{c}}$ 特性の改善が見られた。また，Fig. 3 と Fig. 4 を比較す ると, Ti 添加の効果が明瞭にわかる. すなわら, 両図中 のそれぞれ最高の $J_{\mathrm{c}}$ 特性を比較すると，例えば $14 \mathrm{~T}$ での $J_{\mathrm{c}}$ 值は無添加材では $2.7 \times 10^{8} \mathrm{~A} \cdot \mathrm{m}^{-2}$ であるが, Ti 添加 材では $1.2 \times 10^{9} \mathrm{~A} \cdot \mathrm{m}^{-2}$ と 5 倍程度高い値を示す. Fig. 5 に Ti 箔を積層することにより $\mathrm{Ti}$ 添加した $\mathrm{Nb}_{3} \mathrm{Sn}$ 線材の $4.2 \mathrm{~K}, 14.4 \mathrm{~T}$ での $J_{\mathrm{c}}$ 值と熱処理条件の関係を示す. この 線材では Nb-1 mol\% Ti 板を用いた合金添加材に比べて高 温の熱処理を施さないと高い $J_{\mathrm{c}}$ 値は得られない.すなわ ち，一段処理の場合では合金添加材の場合よりも $100 \mathrm{~K}$

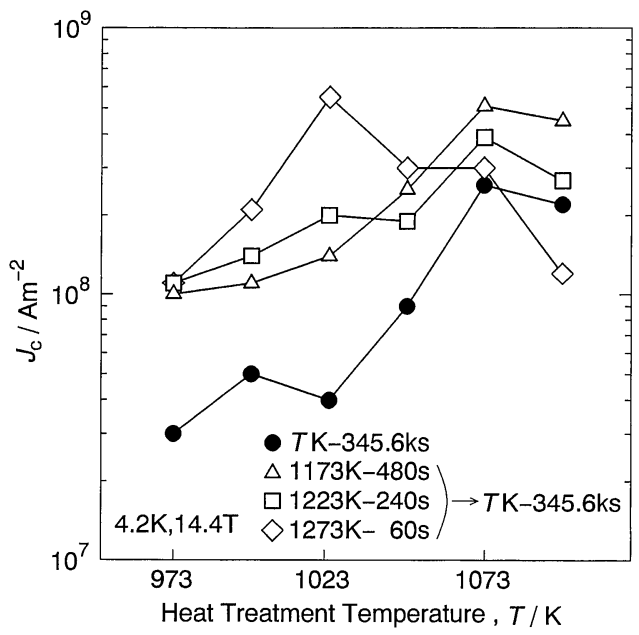

Fig. 5 Variation of $J_{\mathrm{c}}$ at $14.4 \mathrm{~T}$ and $4.2 \mathrm{~K}$ as a function of the heat treatment condition for the CCE processed $\mathrm{Nb}_{3} \mathrm{Sn}$ wires with Ti-foil cladding addition.

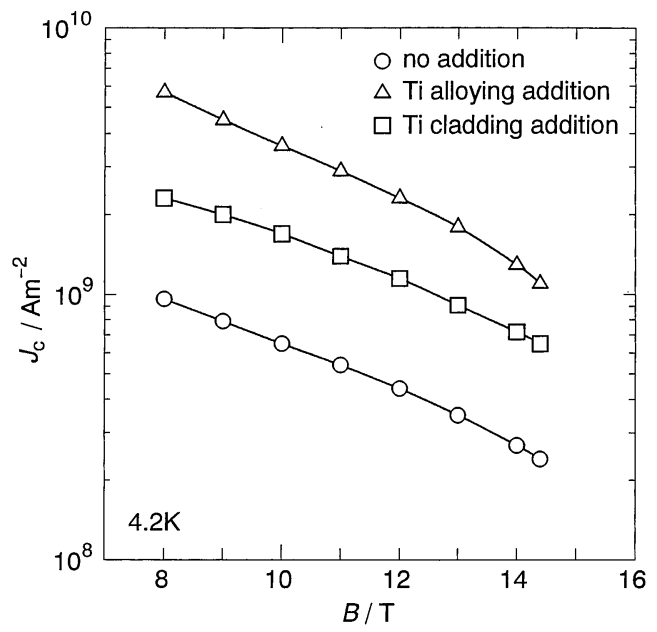

Fig. $6 J_{\mathrm{c}}-B$ curve for the three kinds of CCE processed $\mathrm{Nb}_{3} \mathrm{Sn}$ wires. Each one is heat-treated under the optimum condition.
程度高くする必要があるし，二段処理の場合では一段目の 温度を $50 \mathrm{~K}$ 程度高くするか，もしくは一段目を高温にし ない場合には二段目の温度を $100 \mathrm{~K}$ 程度高くする必要が ある。これは䇴で添加した Tiが合金添加した場合に比べ 拡散しにくいためと考えられる. CCE 法の特徽を生かし て Ti 䇴積層化添加を試みたが，このような $\mathrm{Ti}$ 添加方法 は Nb-Ti 合金の溶解作業が不要であるといら利点はある が，高温熱処理が必要であることを考慮すると必ずしも得 策とは言えない. Fig. 6 に熱処理をとれぞれ最適化した 3 種類の各線材についての $J_{\mathrm{c}}-B$ 曲線を示す.これまでの 報告例と同様に $\mathrm{Ti}$ 添加材の方が優れた $J_{\mathrm{c}}$ 特性を示して拉 り，添加方法としては合金添加の方が高い $J_{\mathrm{c}}$ 特性を示す. これらの $T_{\mathrm{c}}$ はそれぞれ Ti 無添加材が $17.4 \mathrm{~K}$ ，䇴添加材 が $17.7 \mathrm{~K}$ ，合金添加材が $17.8 \mathrm{~K}$ であった. Fig. 7 に高磁

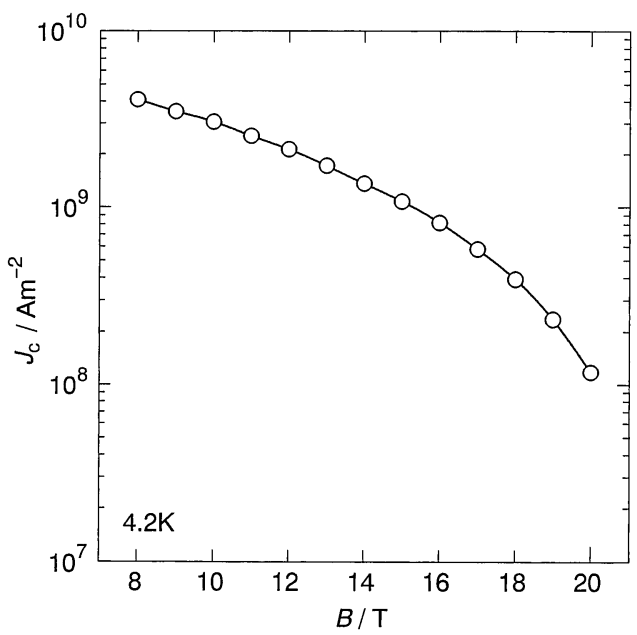

Fig. 7 Best $J_{\mathrm{c}}-B$ curve obtained in the present study.

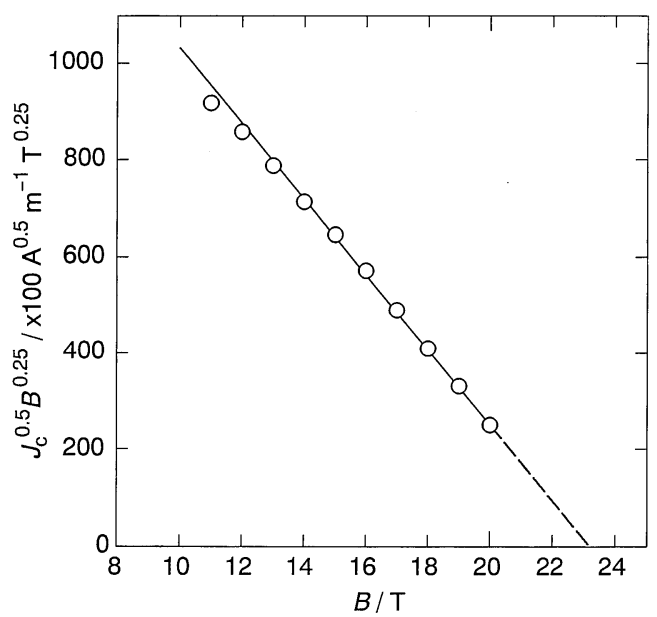

Fig. 8 Kramer plot of $J_{\mathrm{c}}^{0.5} B^{0.25}$ vs. $B$ using the data shown in Fig. 7. 
場 ( 20 T) むでの測定で最高の特性を示した Ti 合金添加 線材の $J_{\mathrm{c}}-B$ 曲線を, Fig. 8 にそのクレーマー・プロッ ト(29)を示す。これより，20 Tでの $J_{\mathrm{c}}$ 值は $1.18 \times 10^{8}$ $\mathrm{A} \cdot \mathrm{m}^{-2}$, また，外挿値としての $B_{\mathrm{c} 2}^{*}(4.2 \mathrm{~K})$ は $23.4 \mathrm{~T}$ であ ることがわかる. 本実験で得られた各超伝導特性はこれま での各種方法により得られている $\mathrm{Nb}_{3} \mathrm{Sn}$ 線材の值と比肩 できるものであり, CCE 法は $\mathrm{Nb}_{3} \mathrm{Sn}$ の線材化方法の一つ として有効であると考えられる.

\section{N. 結言}

$\mathrm{Nb}$ と $\mathrm{Sn}$ の積層薄板を細片化した後, 押出し加工し, その Nb-Sn 複合体を伸線加工し, 最終的に拡散熱処理を 行らクラッド・チップ押出し法(CCE 法)による $\mathrm{Nb}_{3} \mathrm{Sn}$ の 線材化，执よび Ti 添加方法について検討を行った．得ら れた結果を要約すると, 以下のようになる.

（1） Nb-Sn 複合体の加工性は比較的良好で加工度, $R$ (断面減少率 =初期断面積/伸線後の断面積)にして $1.1 \times$ $10^{6}(\mathrm{Nb}$ の厚さに換算すると約 $0.2 \mu \mathrm{m})$ まで断線すること なく伸線できた。

(2) $\mathrm{Nb}_{3} \mathrm{Sn}$ 生成処理後の超伝導特性は Ti 添加材の方 が良好で，本実験範囲内での最高值は $T_{\mathrm{c}}=17.8 \mathrm{~K}, J_{\mathrm{c}}$ $=1.18 \times 10^{8} \mathrm{~A} \cdot \mathrm{m}^{-2}(4.2 \mathrm{~K}, 20 \mathrm{~T}), B_{\mathrm{c} 2}^{*}(4.2 \mathrm{~K})=23.4 \mathrm{~T}$ で あった。

（3）本手法では箔による $\mathrm{Ti}$ 添加も可能であるが，その 場合, 高温の熱処理が必要となる.

最後に, 本研究遂行のため高精度のクラッド圧延をして 頂きました東北大学金属材料研究所の徳能裕巳氏,ならび に超伝導特性の測定に便宜を図って頂きました同所附属強 磁場超伝導材料研究センターの方々に感謝いたします.

\section{文献}

(1) K. Tachikawa: Proc. ICEC-III, Ilifle Science and Technology Publ. Surrey, England, (1970), 339.

( 2 ) A. R. Kaufmann and J. J. Pickett: Bull. Am. Phys. Soc., 15(1970), 838.

( 3 ) E. W. Howlett: U. S. Pat. 3728165, (1970).

(4) K. Tachikawa, T. Asno and T. Takeuchi: Appl. Phys. Lett., 39(1981), 766.
( 5 ) M. Suenaga, W. B. Sampson and T. S. Luhman: IEEE Trans. Mag., MAG-17(1981), 646.

(6) M. Suenaga and W. B. Sampson: Appl. Phys. Lett., $\mathbf{2 0}(1972), 443$.

( 7 ) C. C. Tsuei: Science 180(1973), 57

(8) S. Foner, E. J. McNiff, Jr., B. B. Schwartz and R. Roberge: Appl. Phys. Lett., 31(1977), 853.

( 9 ) Y. Hashimoto, K. Koshizaki and M. Tanaka: Proc. 5th Inter. Cryo. Eng. Conf., Kyoto, Japan, (1974), 332.

(10) R. Borman, L. Schultz and H. C. Freyhardt: Appl. Phys. Lett., 32(1978), 79.

(11) R. Flükiger, S. Foner, E. J. McNiff, Jr., B. B. Schwartz, J. Adams, S. Forman, T. W. Eagar and R. M. Rose: IEEE Trans. Mag., MAG-15(1979), 689.

(12) R. Randall, J. Wong, D. W. Deis, B. J. Shaw and M. R. Daniel: IEEE Trans. Mag., MAG-11(1975), 291.

(13) W. K. McDonald: U. S. Pat. 4262412.

(14) Y. Koike, H. Shiraki, S. Murase, E. Suzuki and M. Ichihara: Appl. Phys. Lett., 29(1976), 384.

(15) S. Murase, M. Koizumi, O. Horigami, H. Shiraki, Y. Koike, E. Suzuki, M. Ichihara, F. Nakane and N. Aoki: IEEE Trans. Mag., MAG-15(1979), 83.

(16) K. Hemachalam and M. R. Pickus: J. Less-Common Metals, 46(1976), 297.

(17) H. Shiraki, S. Nakayama, M. Tanaka, S. Murase, N. Aoki, M. Ichihara, K. Watanabe, K. Noto and Y. Muto: Proc. of MRS International Meeting on Advanced Materials, Vol. 6, Materials Research Society (Pittsburgh), (1989), 43.

（18）斎藤 栄, 池田千里, 池田圭介, 花田修治：日本金 属学会誌, 53(1989), 458 .

（19）斎藤 栄, 池田千里, 池田圭介, 花田修治：日本金 属学会誌, 54(1990), 737.

(20) S. Saito, K. Ikeda, S. Ikeda, A. Nagata and K. Noto: Mater. Trans., JIM, 31(1990), 415.

(21) M. Suenaga, S. Okuda, R. Sabatini, K. Itoh and T. S. Luhman: Adv. Cryo. Eng., 28(1982), 379.

(22) K. Tachikawa, H. Sekine and Y. Iijima: J. Appl. Phys., 53(1982), 5354.

(23) H. Sekine, Y. Iijima, K. Itoh, K. Tachikawa, Y. Tanaka and Y. Furuto: IEEE Trans. Mag., MAG19 (1983), 1429.

（24）志村宗昭, 田中英八郎：日本金属学会会報, 14(1975), 707.

（25）志村宗昭：機械の研究，31(1979), 1039.

（26）小野寺龍太，外本和幸：日本金属学会会報, 26(1987), 1028.

(27) W. Schauer and W. Schelb: IEEE Trans. Mag., MAG-17 (1981), 374.

(28) M. Hong, I. W. Wu, J. W. Morris, Jr., W. Gilbert, W. V. Hassenzahl and C. Taylor: Avd. Cryo. Eng. Mater., 28(1982), 435.

(29) E. J. Kramer: J. Appl. Phys., 44(1973), 1360. 